\title{
Risk factors for perineal and vaginal tears in primiparous women - the prospective POPRACT-cohort study
}

\author{
Markus Harry Jansson ${ }^{1,2^{*}}$ (D, Karin Franzén ${ }^{1,2}$, Ayako Hiyoshi ${ }^{2}$, Gunilla Tegerstedt ${ }^{3}$, Hedda Dahlgren ${ }^{4}$ and
} Kerstin Nilsson ${ }^{2}$

\begin{abstract}
Background: The aim of this study was to estimate the incidence of second-degree perineal tears, obstetric anal sphincter injuries (OASI), and high vaginal tears in primiparous women, and to examine how sociodemographic and pregnancy characteristics, hereditary factors, obstetric management and the delivery process are associated with the incidence of these tears.
\end{abstract}

Methods: All nulliparous women registering at the maternity health care in Region Örebro County, Sweden, in early pregnancy between 1 October 2014 and 1 October 2017 were invited to participate in a prospective cohort study. Data on maternal and obstetric characteristics were extracted from questionnaires completed in early and late pregnancy, from a study-specific delivery protocol, and from the obstetric record system. These data were analyzed using unadjusted and adjusted multinomial and logistic regression models.

Results: A total of 644 women were included in the study sample. Fetal weight exceeding $4000 \mathrm{~g}$ and vacuum extraction were found to be independent risk factors for both second-degree perineal tears (aOR 2.22 (95\% Cl: 1.17, 4.22) and 2.41 (95\% Cl: 1.24, 4.68) respectively) and OASI (aOR 6.02 (95\% Cl: $2.32,15.6)$ and 3.91 (95\% Cl: 1.32, 11.6) respectively). Post-term delivery significantly increased the risk for second-degree perineal tear (aOR 2.44 (95\% Cl: $1.03,5.77)$, whereas, maternal birth positions with reduced sacrum flexibility significantly decreased the risk of second-degree perineal tear (aOR $0.53(95 \% \mathrm{Cl} 0.32,0.90)$ ). Heredity of pelvic floor dysfunction and/or connective tissue deficiency, induced labor, vacuum extraction and fetal head circumference exceeding $35 \mathrm{~cm}$ were independent risk factors for high vaginal tears (aOR 2.32 (95\% Cl 1.09, 4.97), 3.16 (95\% Cl 1.31, 7.62), 2.53 (95\% Cl: $1.07,5.98)$ and $3.07(95 \% \mathrm{Cl} 1.5,6.3)$ respectively).

(Continued on next page)

\footnotetext{
* Correspondence: markus.jansson@oru.se

'Department of Obstetrics and Gynecology, Örebro University Hospital, Örebro, Sweden

${ }^{2}$ School of Medical Sciences, Faculty of Health and Medicine, Örebro University, SE-701 82 Örebro, Sweden

Full list of author information is available at the end of the article
}

C C The Author(s). 2020 Open Access This article is licensed under a Creative Commons Attribution 4.0 International License, which permits use, sharing, adaptation, distribution and reproduction in any medium or format, as long as you give appropriate credit to the original author(s) and the source, provide a link to the Creative Commons licence, and indicate if changes were made. The images or other third party material in this article are included in the article's Creative Commons licence, unless indicated otherwise in a credit line to the material. If material is not included in the article's Creative Commons licence and your intended use is not permitted by statutory regulation or exceeds the permitted use, you will need to obtain permission directly from the copyright holder. To view a copy of this licence, visit http://creativecommons.org/licenses/by/4.0/. The Creative Commons Public Domain Dedication waiver (http://creativecommons.org/publicdomain/zero/1.0/) applies to the data made available in this article, unless otherwise stated in a credit line to the data. 


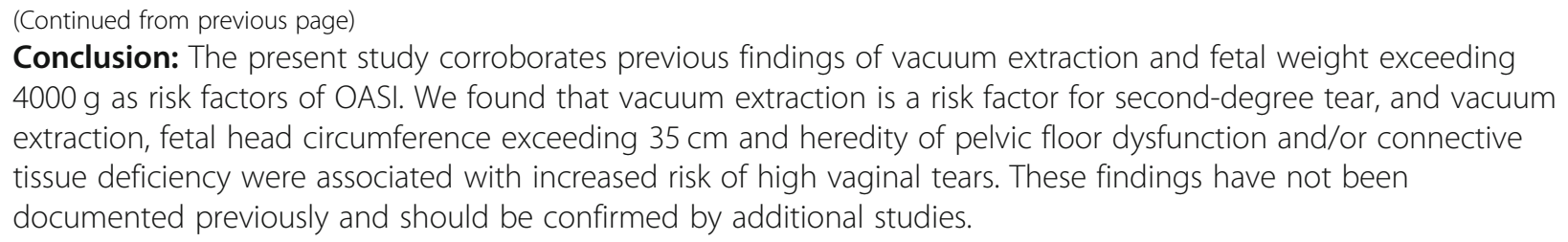

Keywords: High obstetric vaginal tear, Obstetric anal sphincter injuries, Perineal tears, Risk factors, Second-degree perineal tears

\section{Background}

Perineal tears affect about $80 \%$ of women during childbirth, with primiparous women being affected more frequently than multiparous women $[1,2]$. The rate of second-degree perineal tears, which involves the vagina and/or perineal muscle, has been reported to be 35.1$78.3 \%$ among primiparous women and $34.8-39.6 \%$ among multiparous women [1-3], while third- and fourth-degree tears, which involve varying degrees of injury to the anal sphincters, occur in $5.1-8.3 \%$ of primiparous women and $1.8-2.8 \%$ of multiparous women [1, 2, 4, 5]. Between 1990 and 2016, the incidence of thirdand fourth-degree perineal tears among primiparous women in Sweden rose from 2.9 to 5.1\% [6].

Obstetric anal sphincter injuries (OASI) are the largest obstetric risk factor for developing anal incontinence in women [7], so these tears merit particular attention. However, although less attention has been paid, second-degree tears alone may impair sexual function [8] and increase the risk of future pelvic organ prolapse [9], and high vaginal tears have been associated with increased risk for levator muscle avulsion [10]. But the incidence and risk factors of these tears have been poorly investigated.

Various interventions have been attempted to prevent perineal tears, but few have been proven to reduce the incidence of severe perineal tears. There is moderatequality evidence that warm compresses applied to the perineum during delivery and perineal massage can reduce the risk of OASI [11]. Episiotomy has been shown to be protective against OASI in instrumental vaginal delivery $[12,13]$, but in spontaneous vaginal delivery the risk of severe perineal trauma is lower when episiotomy is used restrictively rather than routinely [14]. Randomized controlled studies have not shown any advantage of manual perineal support in reducing OASI [11]. An educational program developed in Finland including a specific technique of manual perineal support and mediolateral episiotomy on indication has been introduced in many obstetrics units in the Nordic countries, but the evidence for this intervention is extremely limited [15]. A non-randomized study from Sweden showed that a multifaceted intervention consisting of spontaneous pushing, birth positions with flexibility in the sacroiliac joints, and a two-step head-to-body delivery significantly reduced second degree tears, but these results have not yet been reproduced [3]. There is a need for new interventions to prevent severe perineal tears, and one way to approach such measures is epidemiologic research regarding risk factors for perineal and high vaginal tears.

Instrumental delivery $[4,5]$, protracted second stage of labor [5, 16], birth weight greater than $4 \mathrm{~kg}[16]$, and fetal occipito-posterior presentation $[4,16]$ have been shown to be independent risk factors for OASI in several retrospective studies. Retrospective studies have generally focused on OASI, whereas second-degree tears have almost exclusively been reserved for prospective observational studies. Only six articles based on prospective observation studies of OASI and/or other perineal tears were identified in an extensive PubMed search [1,2,17-20], and only two of these articles included second-degree perineal tears $[1,2]$.

The aim of this study was to estimate the incidence of second-degree perineal tears, OASI (defined as any third or fourth degree perineal tear), and high vaginal tears in primiparous women, and to examine how sociodemographic and pregnancy characteristics, hereditary factors, obstetric management and the delivery process are associated with the incidence of these tears.

\section{Methods \\ Study design and population}

We conducted a prospective cohort study in the Region Örebro County, Sweden, named the Pelvic Floor In Pregnancy And Childbirth (POPRACT) study. All eligible nulliparous women registering for maternity health care in early pregnancy between 1 October 2014 and 1 October 2017 were informed about the study and asked if they wanted to participate by the midwife in charge. Antenatal care is free of charge in Sweden, and almost all women attend maternity health care. Exclusion criteria were first visit at maternity health care after 15 weeks +6 days of gestation or insufficient knowledge of the Swedish language to complete the questionnaires used in the study. Participants were asked to complete web-based questionnaires on four occasions: at entry into the study in early pregnancy, at 36 weeks of gestation, at 8 weeks postpartum, and at 1 year postpartum. 
Patient-reported data were managed in the cloud-based tool esMaker 3.0 (Entergate AB, Sweden) in accordance with the General Data Protection Regulation of the European Union. The questionnaires included items on general health, socioeconomic status, heredity of pelvic floor dysfunction and connective tissue deficiency, selfreported pelvic floor dysfunction [21, 22] quality of life related to pelvic floor dysfunction [23] and sexual function related to pelvic floor dysfunction [24], see Additional file 1.

\section{Study size}

The present study is a first report from the POPRACT study that aims at studying risk factors for perineal and vaginal birth trauma and subsequent impact on pelvic floor dysfunction including Quality of Life and sexual function. Given the multiple outcomes with unknown incidence, the required sample size for the whole study was difficult to estimate precisely. Inclusion was terminated after three years when slightly more than 1000 women had been included which was judged to be sufficient for detecting risk factors for most outcomes although perhaps not for rare risk factors. For perineal tears, given the incidence reported in the literature for OASI of 5.1-8.3\% [1, 2, 4, 5] and significantly higher for second degree tears, a study population of 1000 women was judged considered to be sufficient to identify risk factors of clinical importance.

\section{Exposure measures}

The following patient-reported data from the first and second questionnaires (i.e. before delivery) were analyzed as potential risk factors for perineal tears and vaginal tear: level of education, heredity of pelvic floor disorders and/or connective tissue deficiency, symptoms of stress urinary incontinence, and symptoms of pelvic organ prolapse. Heredity of pelvic floor disease was defined as mother or sister having undergone surgery due to pelvic organ prolapse, urinary incontinence, inguinal hernia, or varicose veins. Stress urinary incontinence was defined as reporting urine leakage "often" or "sometimes" during physical strain. Symptoms of pelvic organ prolapse was defined as responding "often" or "sometimes" to the question about the sensation of vaginal bulging. Patientreported data about symptoms of pelvic floor dysfunction and quality of life and sexual function related to pelvic floor dysfunction after delivery will be presented in separate scientific publications.

Participating women had their delivery at either of the two delivery wards in Region Örebro County, which are located at Örebro University Hospital and at Karlskoga Hospital. Delivery was assisted by a midwife under ordinary circumstances or by an obstetrician in case of instrumental delivery. Diagnosis of first- and second-degree perineal tears was made by a midwife. In cases of suspected third- or fourth-degree perineal tear or a high vaginal tears, an obstetrician was consulted for an assessment and suturing. After delivery, vaginal examination, and suturing if necessary, the midwife (in co-operation with the obstetrician when needed) completed a study protocol containing specific questions about delivery characteristics, perineal and vaginal tears, and suturing. The part of the protocol regarding perineal tears and suturing has been validated in a previous study [25]. The extent of the perineal or vaginal tear was judged by eye by the midwife or obstetrician, and were classified according to the Royal College of Obstetricians and Gynaecologists classification of perineal tears [26] and the ICD-10 classification of high vaginal tear; that is, a vaginal tear extending above the distal third of the vagina [27]. These classifications are used in the current obstetric record system and are described in the above-mentioned protocol. In case of episiotomy the perineal tear was classified as second-degree at minimum. In women who had both episiotomy and a perineal tear of third or fourth degree, the classification of perineal tear remained unchanged. In order to avoid confounding the incidence and risk factor analysis of perineal tears, women having an episiotomy were excluded from the these analyses. Information regarding oxytocin augmentation during active second stage of labor, use of episiotomy, manual perineal protection, and application of fetal scalp electrode was retrieved from the mentioned study protocol. Data concerning BMI at maternity health care registration in early pregancy, smoking at maternity health care registration in early pregnancy, maternal age at delivery, gestational age at birth, whether delivery started spontaneously or was induced, administration of epidural analgesia, duration of active second stage of labor, maternal position at birth, mode of delivery, fetal presentation, fetal birth weight, and fetal head circumference were extracted from the obstetric record system (Obstetrix version 2.16.0.200, Cerner Corporation, Sweden) using an accessory program (Obstetrix Förlossningsliggare version 2.16.0.200, Cerner Corporation, Sweden). According to the midwife-in-chief at the participating delivery wards, the practice at the time of the study was to define active second stage of labor as active pushing. Variables were categorized as follows: age was categorized into $\leq 25$ years and $>25$ years; BMI into $\leq 25 \mathrm{~kg} / \mathrm{m}^{2}, 25.1-30 \mathrm{~kg} / \mathrm{m}^{2}$ and $>$ $30 \mathrm{~kg} / \mathrm{m}^{2}$; gestational age at delivery into preterm $(<37+$ $0)$, term $(37+0-42+0)$, and postterm $(>42+0)$; duration of active second stage of labor into $\leq 15 \mathrm{~min}, 16-60 \mathrm{~min}$, and $>60 \mathrm{~min}$; mode of delivery into spontaneous and vacuum extraction; fetal presentation into occiput anterior and occiput posterior; fetal weight into $\leq 4000 \mathrm{~g}$ and > $4000 \mathrm{~g}$; and fetal head circumference into $\leq 35 \mathrm{~cm}$ and > $35 \mathrm{~cm}$. Maternal position at birth was categorized into 1) flexible sacrum positions, including squatting, kneeling 


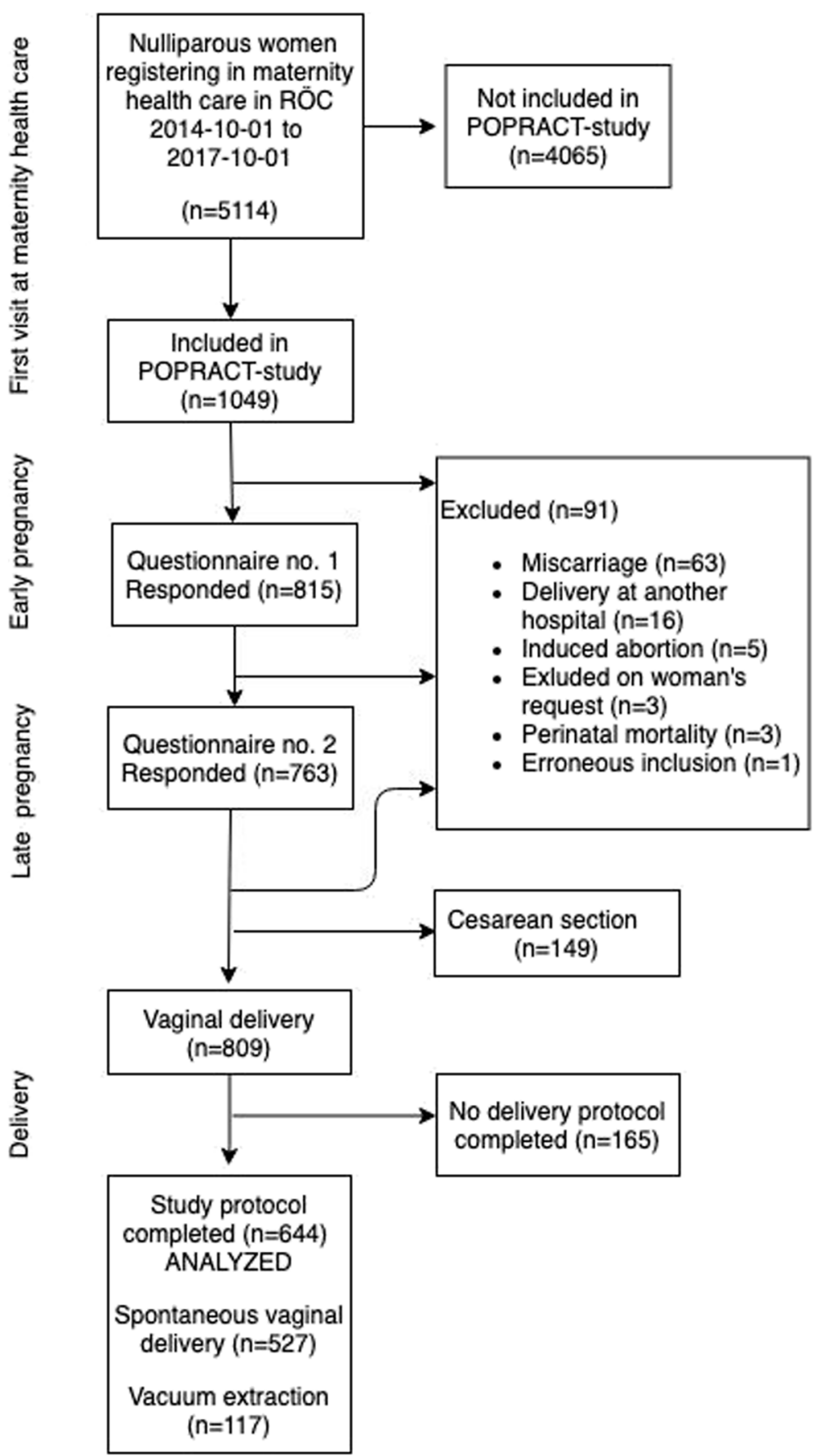

Fig. 1 Flow chart illustrating the inclusion of the study sample. RÖC, Region Örebro County; POPRACT study, Pelvic Floor In Pregnancy And Childbirth study

and lateral; and 2) positions with reduced sacrum flexibility, including lithotomy, supine and sitting.

\section{Outcome measures}

The primary outcome measure was perineal tear, which was divided into three groups: 1) intact perineum or first degree tear (defined as the reference category), 2) second-degree tear, and 3) third- or fourth-degree tear, i.e. OASI. Vaginal tears, were categorized into two groups: 1) no or low vaginal tear (the reference category) and 2) high vaginal tear.

\section{Statistical analyses}

Relationships between potential risk factors and different degrees of perineal and vaginal tears were evaluated 
using unadjusted and adjusted multivarable regression models. Multinomial logistic regression was used for perineal tears, and logistic regression was used for vaginal tears. In the multivariate models for perineal tear, all potential risk factors were entered in the model and mutually adjusted for except heredity of pelvic floor dysfunction and/or connective tissue deficiency, stress urinary incontinence, episiotomy, whether hand or arm was the presenting part, and fetal head $>35 \mathrm{~cm}$. In the case of vaginal tear, all risk factors except stress urinary incontinence and fetal weight $>4000 \mathrm{~g}$ were entered in the adjusted model. Assessment of potential multicollinearity among risk factors showed no collinearity issues; all variance inflation factors were $<1.6$. An interaction between fetal weight and delivery mode on the risk of perineal tear was examined using interaction tests.

An additional risk factor analysis including women having an episiotomy was performed. In this analysis, episiotomy was evaluated as a risk factor of OASI, but was not included in the final analysis due to too few women having the combination of episiotomy and OASI.

Differences between vaginally delivered women with and without a registered study-specific delivery protocol were compared using a t-test in the case of supposed parametric continuous variables, the Wilcoxon ranksum test in the case of supposed non-parametric continuous variables, and a chi-squared test in the case of categorical variables. Data were analyzed using version Stata/SE V13 (StataCorp LP, College Station, TX).

\section{Results}

Figure 1 presents the inclusion of the study sample. A total of 1049 women were included in the POPRACT study. Of the study population remaining after exclusion, 809 women had a vaginal delivery. Delivery was documented in the dedicated study protocol for 644 of these women, who thus constituted the present study sample. The analysis of risk factors in relation to perineal and vaginal tears included 443 and 421 women, respectively, after excluding women with missing data in relevant variables.

Baseline and obstetric and baseline characteristics of the study sample are shown in Table 1 and Table 2, respectively. The sample had a mean $( \pm \mathrm{SD})$ age of $28.7 \pm 3.7$ years (range: $18-41$ years), BMI of $24.5 \pm 4.4$ $\mathrm{kg} / \mathrm{m}^{2}\left(16.4-44.0 \mathrm{~kg} / \mathrm{m}^{2}\right)$, gestational age at birth of 40 weeks +1 day \pm 1 week +3 days ( 34 weeks +1 day 42 weeks +5 days), fetal birth weight of $3513 \pm 472 \mathrm{~g}$ (1730-5140 g), and fetal head circumference of $34.8 \pm$ $1.5 \mathrm{~cm}(28.0-38.5 \mathrm{~cm})$. Smoking, symptoms of pelvic organ prolapse during late pregnancy, and lack of manual perineal protection were considered as potential risk factors but were excluded from the analysis of risk factors presented below due to too few
Table 1 Baseline characteristics of the study population

\begin{tabular}{|c|c|}
\hline & n (\%) \\
\hline \multicolumn{2}{|l|}{ Age } \\
\hline$\leq 25$ years & $114(17.7)$ \\
\hline $26-30$ years & $347(53.9)$ \\
\hline $31-35$ years & $155(24.1)$ \\
\hline$>35$ years & $28(4.4)$ \\
\hline Missing & 0 \\
\hline \multicolumn{2}{|l|}{ BMI } \\
\hline$\leq 25 \mathrm{~kg} / \mathrm{m}^{2}$ & $405(64.5)$ \\
\hline $25.1-30 \mathrm{~kg} / \mathrm{m}^{2}$ & $155(24.7)$ \\
\hline$>30 \mathrm{~kg} / \mathrm{m}^{2}$ & $68(10.8)$ \\
\hline Missing & 16 \\
\hline \multicolumn{2}{|l|}{ Smoking } \\
\hline Yes & $19(3.0)$ \\
\hline No & $605(97.0)$ \\
\hline Missing & 20 \\
\hline \multicolumn{2}{|l|}{ Education } \\
\hline $9-<12$ years & $8(1.5)$ \\
\hline 12 years & $181(33.2)$ \\
\hline University & $357(65.4)$ \\
\hline Missing & 98 \\
\hline \multicolumn{2}{|l|}{ Heredity $^{a}$} \\
\hline Yes & $70(14.4)$ \\
\hline No & $415(85.6)$ \\
\hline Missing & 159 \\
\hline \multicolumn{2}{|c|}{ SUI during late pregnancy } \\
\hline Yes & $116(22.2)$ \\
\hline No & $406(77.8)$ \\
\hline Missing & 122 \\
\hline \multicolumn{2}{|c|}{ Symptoms of POP during late pregnancy } \\
\hline Yes & $22(4.2)$ \\
\hline No & $501(95.8)$ \\
\hline Missing & 121 \\
\hline
\end{tabular}

Baseline characteristics of the study population. Women where information is

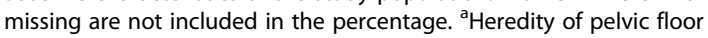
dysfunction and/or connective tissue deficiency. BMI, body mass index; POP, pelvic organ prolapse; SUI, stress urinary incontinence

exposed women. No statistically significant differences were found between the women whose data were collected according to study-specific delivery protocol registered $(n=644)$ and those excluded due to missing study protocol $(n=165)$, except regarding use of epidural analgesia and duration of active second stage of labor. In the excluded group, epidural use was lower $(38.2 \%)$ and the mean duration of active second stage of labor was longer $(48.7 \pm 35.4 \mathrm{~min}$; range: 1 $189 \mathrm{~min})$. 
Table 2 Obstetric characteristics of the study population

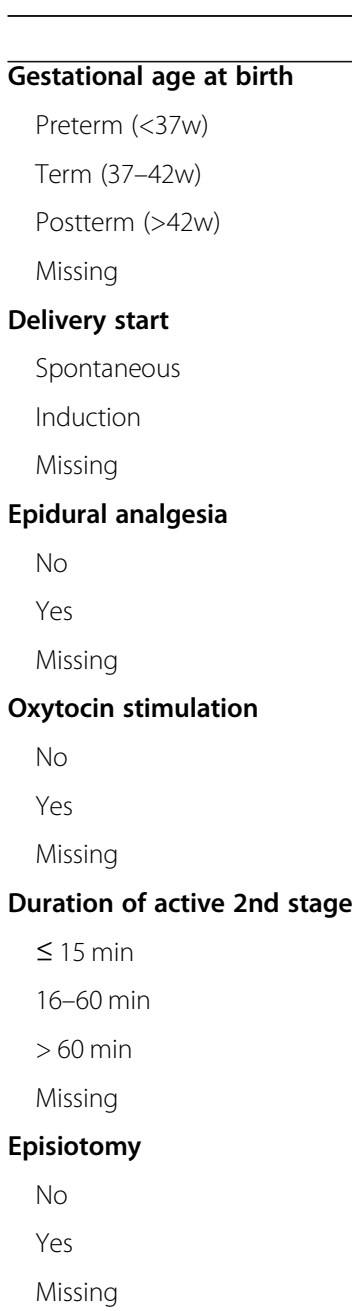

\section{Maternal position at birth}

Lithotomy
Squatting
Kneeling
Supine
Lateral
Sitting
Standing
Missing
Mode of delivery
Spontaneous
Instrumental
Missing
Manual perineal protection
None
Fetal head support only
Perineal head support only
Combined support

n (\%)

$21(3.3)$

$552(85.7)$

$60(9.3)$

11

512 (79.6)

$131(20.4)$

1

$314(48.8)$

$330(51.2)$

$306(48.5)$

$325(51.5)$

12

$124(19.9)$

$346(55.5)$

$154(24.7)$

20

$579(91.3)$

$55(8.7)$

9

$353(55.6)$

$1(0.16)$

$11(1.7)$

$18(2.8)$

98 (15.2)

$153(23.8)$

$1(0.16)$

9

$527(81.8)$

$117(18.2)$

0

$8(1.3)$

$30(4.8)$

$82(13.0)$

409 (65.0)
Table 2 Obstetric characteristics of the study population (Continued)

\begin{tabular}{ll}
\hline & $\mathbf{n ~ ( \% )}$ \\
\hline Unspecified support & $100(15.9)$ \\
Missing & 15 \\
Fetal scalp electrode & \\
No & $279(44.2)$ \\
Yes & $352(55.8)$ \\
Missing & 12
\end{tabular}

\section{Fetal presentation}

Occiput anterior

Occiput posterior

Breech

0

Missing

10

Fetal birth weight

$$
\leq 4000 \mathrm{~g}
$$

$>4000 \mathrm{~g}$

$102(15.9)$

Missing

Fetal head circumference

$$
\leq 35 \mathrm{~cm}
$$

$>35 \mathrm{~cm}$

363 (56.6)

Missing

3

Number of births

$$
\text { Singleton }
$$

Twins

Missing

Obstetric characteristics of the study population. Women where information is missing are not included in the percentage

Incidence of perineal, vaginal, and other vulvar tears

Table 3 presents the incidence of vaginal, perineal, and other vulvar tears. Almost half of the women (47.6\%) contracted any labial tear requiring suturing. Anterior tears close to the clitoris or urethra were less common than labial tears, affecting $15.3 \%$ of the sample. Only $14.9 \%$ of women avoided any vaginal tear. The vast majority $(71.1 \%)$ of women with vaginal tear had a low tear, whereas $14.0 \%$ contracted a high vaginal tear. About one third (33.7\%) of these women had an intact perineum, while the remaining two thirds had some degree of perineal tear. Seconddegree tears constituted the majority of tears $(40.6 \%)$. The incidences of third-degree tears of class $\mathrm{A}, \mathrm{B}$, and $\mathrm{C}$ were $4.1,1.1$, and $2.1 \%$ respectively. Only two women $(0.35 \%)$ contracted a fourth-degree perineal tear. The incidence of perineal tear in women having an episiotomy or with no information regarding episiotomy, respectively, is presented separately. 
Table 3 Distribution of vaginal, perineal, and other vulvar tear

\begin{tabular}{|c|c|}
\hline Labial tears $^{\mathrm{a}}(n=644)$ & n (\%) \\
\hline None & $\begin{array}{l}329 \\
(52.4)\end{array}$ \\
\hline Yes & $\begin{array}{l}299 \\
(47.6)\end{array}$ \\
\hline Missing & 16 \\
\hline Anterior tears $^{\mathbf{b}}(n=644)$ & n (\%) \\
\hline None & $\begin{array}{l}511 \\
(84.7)\end{array}$ \\
\hline Yes & $92(15.3)$ \\
\hline Missing & 41 \\
\hline Vaginal tear $(n=644)$ & n (\%) \\
\hline None & $91(14.9)$ \\
\hline Low $^{c}$ & $\begin{array}{l}433 \\
(71.1)\end{array}$ \\
\hline $\mathrm{High}^{\mathrm{d}}$ & $85(14.0)$ \\
\hline Missing & 35 \\
\hline Degree of perineal tear $(n=580)$ & n (\%) \\
\hline None & $\begin{array}{l}191 \\
(33.7)\end{array}$ \\
\hline First-degree & $\begin{array}{l}103 \\
(18.2)\end{array}$ \\
\hline Second-degree & $\begin{array}{l}230 \\
(40.6)\end{array}$ \\
\hline Third-degree (A) & $23(4.1)$ \\
\hline Third-degree (B) & $6(1.1)$ \\
\hline Third-degree (C) & $12(2.1)$ \\
\hline Fourth-degree & $2(0.35)$ \\
\hline Missing & 13 \\
\hline $\begin{array}{l}\text { Degree of perineal tear, women with episiotomy } \\
(n=55)\end{array}$ & n (\%) \\
\hline Episiotomy without OASI & $51(94.4)$ \\
\hline Episiotomy and third-degree (A) & $1(1.9)$ \\
\hline Episiotomy and third-degree (B) & $2(3.7)$ \\
\hline Missing & 1 \\
\hline $\begin{array}{l}\text { Degree of perineal tear, women with missing } \\
\text { information regarding episiotomy }(n=9)\end{array}$ & n (\%) \\
\hline None & $3(50)$ \\
\hline First-degree & $1(16.7)$ \\
\hline Second-degree & $2(33.3)$ \\
\hline Missing & 3 \\
\hline
\end{tabular}

Distribution of vaginal, perineal, and other vulvar tear. An individual woman may have labial, anterior, vaginal and perineal tear concomitantly and thus be part of several tear groups. Missing information is due to incomplete information in the delivery protocols and is not included in the percentage. alabial tears requiring suturing; ${ }^{b}$ anterior tears close to clitoris or urethra, not related to female genital mutilation; ' ${ }^{C}$ vaginal tear where only the distal third of vagina is engaged; ${ }^{d}$ vaginal tear more extensive than the distal third of vagina. OASI,obstetric anal sphincter injury
Odds ratios for the risk factors of second-degree perineal tear and OASI

Table 4 presents the unadjusted and adjusted odds ratios for second-degree perineal tear and for OASI, respectively. Women with second-degree perineal tear were more likely to be older than 25 years, to have a post-term delivery, to be exposed to oxytocin augmentation, to have an active second stage shorter or equal to $15 \mathrm{~min}$, to have delivery assisted by vacuum extraction, to have fetal heart beat monitored by scalp electrode, and to have a child heavier than $4000 \mathrm{~g}$ or with a head circumference exceeding 35 $\mathrm{cm}$, compared to women who did not have a tear or had a tear of first degree (the reference). After adjustment, postterm delivery, vacuum extraction, and fetal weight exceeding $4000 \mathrm{~g}$ remained as risk factors significantly increasing the risk of second-degree perineal tear. In the adjusted model, maternal birth positions with reduced sacrum flexibility, significantly decreased the risk of second-degree perineal tear, despite not being significant in the unadjusted model. Women with OASI were more likely to use epidural analgesia, to have delivery assisted by vacuum extraction, to have fetal heart beat monitored by scalp electrode, and to have a child heavier than $4000 \mathrm{~g}$ or with a head circumference exceeding $35 \mathrm{~cm}$, compared to the reference. After adjustment, vacuum extraction and fetal weight $>4000 \mathrm{~g}$ remained as risk factors significantly increasing the risk of OASI. In the analysis including women having an episiotomy, age was an independent risk factor of second-degree perineal tear, see additional file 2. Otherwise no significant differences were found.

\section{Odds ratios for high vaginal tear}

Table 5 shows the unadjusted and adjusted odds ratios for high vaginal tear. Women with a high vaginal tear were more likely to report heredity of pelvic floor dysfunction and/or connective tissue deficiency, to have induced labor, to deliver a baby whose hand or arm was the presenting fetal part, and to deliver a baby whose head circumference exceeded $35 \mathrm{~cm}$, compared to referent women with no or low vaginal tear. After adjustment, heredity of pelvic floor dysfunction and/or connective tissue deficiency, induced labor, and fetal head circumference $>35 \mathrm{~cm}$ remained as risk factors, significantly increasing the risk of high vaginal tear. In the adjusted model, vacuum extraction significantly increased the risk of high vaginal tear, whereas augmentation of oxytocin significantly reduced the risk of high vaginal tear, despite none of them being significantly associated with high vaginal tear in the unadjusted model.

Odds ratios for the combined effect of delivery mode and fetal weight on the risk of perineal tear

Table 6 shows the odds ratios, before and after adjustment, for second-degree perineal tear and OASI, 
Table 4 Unadjusted and adjusted odds ratios for risk factors for perineal tear

\begin{tabular}{|c|c|c|c|c|}
\hline \multirow[t]{2}{*}{$n=443$} & \multicolumn{2}{|c|}{ 2nd degree $(n=182)$} & \multicolumn{2}{|l|}{ OASI $(n=31)$} \\
\hline & OR (95\% Cl) & aOR $(95 \% \mathrm{Cl})$ & OR $(95 \% \mathrm{Cl})$ & aOR $(95 \% \mathrm{Cl})$ \\
\hline \multicolumn{5}{|l|}{ Age } \\
\hline$\leq 25$ years & Reference & Reference & Reference & Reference \\
\hline$>25$ years & $1.78(1.05,3.04)^{*}$ & $1.62(0.90,2.93)$ & $1.41(0.51,3.86)$ & $1.36(0.40,4.56)$ \\
\hline \multicolumn{5}{|l|}{ BMI } \\
\hline$\leq 25 \mathrm{~kg} / \mathrm{m}^{2}$ & Reference & Reference & Reference & Reference \\
\hline $25.1-30 \mathrm{~kg} / \mathrm{m}^{2}$ & $1.02(0.64,1.61)$ & $1.11(0.68,1.81)$ & $1.21(0.52,2.8)$ & $1.04(0.41,4.56)$ \\
\hline$>30 \mathrm{~kg} / \mathrm{m}^{2}$ & $1.19(0.63,2.22)$ & $1.22(0.61,2.41)$ & $0.63(0.14,2.85)$ & $0.38(0.07,1.99)$ \\
\hline \multicolumn{5}{|l|}{ Education } \\
\hline 9 to $<12$ years & $0.3(0.03,2.69)$ & $0.35(0.04,3.47)$ & $3.32(0.57,19.2)$ & $4.01(0.54,29.8)$ \\
\hline 12 years & $0.86(0.57,1.3)$ & $0.93(0.59,1.46)$ & $0.58(0.24,1.42)$ & $0.56(0.20,1.55)$ \\
\hline University & Reference & Reference & Reference & Reference \\
\hline \multicolumn{5}{|c|}{ Heredity $^{\mathbf{a}}(n=397)$} \\
\hline No & Reference & $\mathrm{NE}$ & Reference & $\mathrm{NE}$ \\
\hline Yes & $1.38(0.77,2.46)$ & $\mathrm{NE}$ & $1.63(0.57,4.7)$ & $\mathrm{NE}$ \\
\hline \multicolumn{5}{|c|}{ SUI in late pregnancy } \\
\hline No & Reference & $\mathrm{NE}$ & Reference & $\mathrm{NE}$ \\
\hline Yes & $0.69(0.42,1.12)$ & $\mathrm{NE}$ & $1.59(0.7,3.63)$ & $\mathrm{NE}$ \\
\hline \multicolumn{5}{|l|}{ GA at birth } \\
\hline Preterm/term & Reference & Reference & Reference & Reference \\
\hline Postterm & $2.23(1.11,4.47)^{*}$ & $2.44(1.03,5.77)^{*}$ & $2.29(0.7,7.45)$ & $1.48(0.34,6.50)$ \\
\hline \multicolumn{5}{|l|}{ Delivery start } \\
\hline Spontaneous & Reference & Reference & Reference & Reference \\
\hline Induction & $1.16(0.7,1.93)$ & $0.73(0.38,1.40)$ & $1.76(0.73,4.22)$ & $1.31(0.43,4.00)$ \\
\hline \multicolumn{5}{|c|}{ Epidural analgesia } \\
\hline No & Reference & Reference & Reference & Reference \\
\hline Yes & $1.20(0.81,1.77)$ & $0.97(0.63,1.5)$ & $2.41(1.09,5.35)^{*}$ & $1.62(0.68,3.87)$ \\
\hline \multicolumn{5}{|c|}{ Oxytocin stimulation } \\
\hline No & Reference & Reference & Reference & Reference \\
\hline Yes & $1.53(1.03,2.26)^{*}$ & $1.18(0.74,1.9)$ & $1.9(0.89,4.06)$ & $0.85(0.34,2.13)$ \\
\hline \multicolumn{5}{|c|}{ Duration of active 2 nd stage } \\
\hline$\leq 15 \min$ & $0.66(0.39,1.14)^{*}$ & $0.69(0.39,1.21)$ & $1.08(0.43,2.76)$ & $1.22(0.44,3.4)$ \\
\hline $16-60 \mathrm{~min}$ & Reference & Reference & Reference & Reference \\
\hline$>60 \min$ & $1.09(0.68,1.74)$ & $0.99(0.6,1.62)$ & $0.84(0.32,2.23)$ & $0.59(0.21,1.72)$ \\
\hline \multicolumn{5}{|c|}{ Maternal position at birth } \\
\hline \multicolumn{5}{|l|}{ Flexible } \\
\hline sacrum & Reference & Reference & Reference & Reference \\
\hline \multicolumn{5}{|l|}{ positions } \\
\hline Reduced & $0.94(0.59,1.49)$ & $0.53(0.32,0.90)^{*}$ & $1.07(0.42,2,75)$ & $0.63(0.21,1.85)$ \\
\hline \multicolumn{5}{|l|}{ sacrum } \\
\hline \multicolumn{5}{|l|}{ flexibility } \\
\hline \multicolumn{5}{|l|}{ Mode of delivery } \\
\hline Spontaneous & Reference & Reference & Reference & Reference \\
\hline
\end{tabular}


Table 4 Unadjusted and adjusted odds ratios for risk factors for perineal tear (Continued)

\begin{tabular}{|c|c|c|c|c|}
\hline \multirow[t]{2}{*}{$n=443$} & \multicolumn{2}{|c|}{ 2nd degree $(n=182)$} & \multicolumn{2}{|l|}{ OASI $(n=31)$} \\
\hline & OR (95\% Cl) & aOR $(95 \% \mathrm{Cl})$ & $\overline{\mathrm{OR}}(95 \% \mathrm{Cl})$ & aOR $(95 \% \mathrm{Cl})$ \\
\hline extraction & $2.37(1.29,4.34)^{*}$ & $2.41(1.24,4.68)^{*}$ & $3.86(1.52,9.8)^{*}$ & $3.91(1.32,11.6)^{*}$ \\
\hline \multicolumn{5}{|l|}{ Fetal scalp electrode } \\
\hline No & Reference & Reference & Reference & Reference \\
\hline Yes & $1.28(0.87,1.9)^{*}$ & $1.13(0.73,1.77)$ & $3.03(1.3,7.05)^{*}$ & $2.55(0.98,6.61)$ \\
\hline \multicolumn{5}{|l|}{ Fetal presentation } \\
\hline Occiput anterior & Reference & Reference & Reference & Reference \\
\hline Occiput posterior & $1.27(0.44,3.7)$ & $1.38(0.45,4.21)$ & $2.2(0.44,11.08)$ & $3.22(0.53,19.5)$ \\
\hline \multicolumn{5}{|c|}{ Hand or arm presenting fetal part } \\
\hline No & Reference & $\mathrm{NE}$ & Reference & $\mathrm{NE}$ \\
\hline Yes & $1.05(0.57,1.91)$ & $\mathrm{NE}$ & $0.81(0.23,2.83)$ & $\mathrm{NE}$ \\
\hline \multicolumn{5}{|l|}{ Fetal weight } \\
\hline$\leq 4000 \mathrm{~g}$ & Reference & Reference & Reference & Reference \\
\hline$>4000 \mathrm{~g}$ & $2.46(1.35,4.49)^{*}$ & $2.22(1.17,4.22)^{*}$ & $6.11(2.55,14.6)^{*}$ & $6.02(2.32,15.6)^{*}$ \\
\hline \multicolumn{5}{|c|}{ Fetal head circumference } \\
\hline$\leq 35 \mathrm{~cm}$ & Reference & $\mathrm{NE}$ & Reference & $\mathrm{NE}$ \\
\hline$>35 \mathrm{~cm}$ & $1.87(1.26,2.77)^{*}$ & NE & $3.94(1.63,9.51)^{*}$ & $\mathrm{NE}$ \\
\hline
\end{tabular}

Unadjusted and adjusted odds ratios for risk factors for perineal tear using multinomial logistic regression. The group of women with second-degree perineal tear and OASI were compared with women with no or first-degree perineal tear. Women having an episiotomy were excluded from the analysis. Sample size for the unadjusted OR for heredity, SUI, hand or arm presenting fetal part and fetal head circumference was based on $n=397, n=415, n=441$ and $n=442$, respectively. ${ }^{a}$ Heredity of pelvic floor dysfunction and/or connective tissue deficiency; *Significant at level $p<0.05$. aOR adjusted odds ratio, BMI body mass index, CI confidence interval, GA gestational age, NE not estimated, OASI obstetric anal sphincter injury, OR odds ratio, SUI stress urinary incontinence

in four different combinations of two risk factors vacuum extraction and fetal weight: 1) women with spontaneous delivery of a child weighing < $4000 \mathrm{~g}, 2$ ) women with spontaneous delivery of a child weighing $\geq 4000 \mathrm{~g}, 3$ ) women with vacuum-assisted delivery of a child weighing $<4000 \mathrm{~g}$, and 4) women with vacuumassisted delivery of a child weighing $\geq 4000$ g. Subgroup 4, in which the two major risk factors were combined, had adjusted ORs for second-degree tear and OASI of 4.8 (95\% CI: $1.20,19.3)$ and 12.7 (95\% CI: $1.65,97.7)$, respectively, and the interaction terms for second-degree perineal tear and for OASI were 0.89 (95\% CI: $0.17,4.66$ ) and 0.30 (95\% CI: 0.03, $3.16)$, respectively, meaning that there was no significant interaction between vacuum extraction and fetal birthweight above $4000 \mathrm{~g}$ (data not shown).

\section{Discussion}

In this prospective study of primiparous women, the incidences of second-degree perineal tear, OASI, and high vaginal tear were $40.6,7.4$, and $14.0 \%$ respectively. Vacuum extraction and fetal weight above $4000 \mathrm{~g}$ were independent risk factors for both second-degree perineal tear and OASI. Post-term delivery significantly increased the risk for second-degree perineal tear, and, surprisingly, maternal birth positions with reduced sacrum flexibility significantly decreased the risk of second-degree perineal tear, whereas none of them were significantly associated with OASI. Heredity of pelvic floor dysfunction and/or connective tissue deficiency, induced labor, vacuum extraction and fetal head circumference exceeding $35 \mathrm{~cm}$ were independent risk factors for high vaginal tear, whereas oxytocin augmentation, unexpectedly, appeared to reduce the risk of high vaginal tear.

To our knowledge, this is one of very few observational studies of perineal tears that include tears of second degree. An extensive PubMed search identified only two observational studies reporting the incidence of second-degree perineal tear $[1,2]$ and only one of these separately analyzed risk factors for second-degree tears [1]. As in the present study, Samuelsson et al. found high infant weight to be an independent risk factor for both second-degree tears and OASI, but in their study vacuum extraction was not an independent risk factor for either degree of tear. We did not find that prolonged active phase of second stage of labor led to any increased risk for either OASI or second-degree tears, whereas Samuelsson et al. found that pushing time $<30 \mathrm{~min}$ decreased the risk of both $[1,17]$. An imprecise definition of the active phase of second stage of labor in the present study might partly explain the difference in the results; a review of the obstetric record of all women with active second stage of labor exceeding $120 \mathrm{~min}$ revealed that in about half of those cases, the midwife 
Table 5 Unadjusted and adjusted odds ratio for the risk of high vaginal tear

\begin{tabular}{|c|c|c|}
\hline \multirow[t]{2}{*}{$n=421$} & \multicolumn{2}{|c|}{ High vaginal tear $(n=55)$} \\
\hline & $\overline{\mathrm{OR}}(95 \% \mathrm{Cl})$ & aOR $(95 \% \mathrm{Cl})$ \\
\hline \multicolumn{3}{|l|}{$\overline{\text { Age }}$} \\
\hline$\leq 25$ years & Reference & Reference \\
\hline$>25$ years & $2.20(0.84,5.73)$ & $2.36(0.77,7.26)$ \\
\hline \multicolumn{3}{|l|}{ BMI } \\
\hline$\leq 25 \mathrm{~kg} / \mathrm{m}^{2}$ & Reference & Reference \\
\hline $25.1-30 \mathrm{~kg} / \mathrm{m}^{2}$ & $1.12(0.57,2.22)$ & $1.15(0.54,2.47)$ \\
\hline$>30 \mathrm{~kg} / \mathrm{m}^{2}$ & $0.97(0.39,2.45)$ & $0.85(0.3,2.37)$ \\
\hline \multicolumn{3}{|l|}{ Education } \\
\hline 9 to $<12$ years & $1.48(0.16,13.53)$ & $5.83(0.45,75.33)$ \\
\hline 12 years & $0.64(0.33,1.24)$ & $0.79(0.38,1.64)$ \\
\hline University & Reference & Reference \\
\hline \multicolumn{3}{|l|}{ Heredity $^{a}$} \\
\hline No & Reference & Reference \\
\hline Yes & $2.21(1.12,4.35)^{*}$ & $2.32(1.09,4.97)^{*}$ \\
\hline \multicolumn{3}{|l|}{ SUI in late pregnancy } \\
\hline No & Reference & $\mathrm{NE}$ \\
\hline Yes & $0.81(0.38,1.74)$ & $\mathrm{NE}$ \\
\hline \multicolumn{3}{|l|}{ GA at birth } \\
\hline Preterm and term & Reference & Reference \\
\hline Postterm & $2.04(0.92,4.55)$ & $0.69(0.23,2.05)$ \\
\hline \multicolumn{3}{|l|}{ Delivery start } \\
\hline Spontaneous & Reference & Reference \\
\hline Induction & $2.64(1.4,4.95)^{*}$ & $3.16(1.31,7.62)^{*}$ \\
\hline \multicolumn{3}{|l|}{ Epidural analgesia } \\
\hline No & Reference & Reference \\
\hline Yes & $0.93(0.53,1.63)$ & $0.78(0.4,1.5)$ \\
\hline \multicolumn{3}{|l|}{ Oxytocin stimulation } \\
\hline No & Reference & Reference \\
\hline Yes & $0.83(0.47,1.47)$ & $0.41(0.2,0.84)^{*}$ \\
\hline \multicolumn{3}{|l|}{ Duration of active 2 nd stage } \\
\hline$\leq 15 \min$ & $0.65(0.27,1.53)$ & $0.71(0.29,1.76)$ \\
\hline $16-60 \mathrm{~min}$ & Reference & Reference \\
\hline$>60 \min$ & $1.05(0.54,2.03)$ & $0.97(0.46,2.02)$ \\
\hline \multicolumn{3}{|l|}{ Episiotomy } \\
\hline No & Reference & Reference \\
\hline Yes & $1.54(0.6,3.91)$ & $1.01(0.34,3.05)$ \\
\hline \multicolumn{3}{|l|}{ Maternal position at birth } \\
\hline Flexible sacrum positions & Reference & Reference \\
\hline Reduced sacrum flexibility & $1.30(0.61,2.77)$ & $1.08(0.46,2.53)$ \\
\hline \multicolumn{3}{|l|}{ Mode of delivery } \\
\hline Spontaneous & Reference & Reference \\
\hline Vacuum extraction & $1.55(0.78,3.06)$ & $2.53(1.07,5.98)^{*}$ \\
\hline
\end{tabular}


Table 5 Unadjusted and adjusted odds ratio for the risk of high vaginal tear (Continued)

\begin{tabular}{|c|c|c|}
\hline \multirow[t]{2}{*}{$n=421$} & \multicolumn{2}{|c|}{ High vaginal tear $(n=55)$} \\
\hline & $\overline{\mathrm{OR}}(95 \% \mathrm{Cl})$ & aOR $(95 \% \mathrm{Cl})$ \\
\hline \multicolumn{3}{|l|}{ Fetal scalp electrode } \\
\hline No & Reference & Reference \\
\hline Yes & $1.59(0.88,2.85)$ & $1.71(0.85,3.42)$ \\
\hline \multicolumn{3}{|l|}{ Fetal presentation } \\
\hline Occiput anterior & Reference & Reference \\
\hline Occiput posterior & $0.43(0.06,3.35)$ & $0.47(0.04,5.07)$ \\
\hline \multicolumn{3}{|c|}{ Hand or arm presenting fetal part } \\
\hline No & Reference & Reference \\
\hline Yes & $2.16(1.03,4.53)^{*}$ & $2.27(0.99,5.24)$ \\
\hline \multicolumn{3}{|l|}{ Fetal weight } \\
\hline$\leq 4000 \mathrm{~g}$ & Reference & $\mathrm{NE}$ \\
\hline$>4000 \mathrm{~g}$ & $1.37(0.65,2.9)$ & $\mathrm{NE}$ \\
\hline \multicolumn{3}{|c|}{ Fetal head circumference } \\
\hline$\leq 35 \mathrm{~cm}$ & Reference & Reference \\
\hline$>35 \mathrm{~cm}$ & $2.71(1.41,5.22)^{*}$ & $3.07(1.5,6.3)^{*}$ \\
\hline
\end{tabular}

entered the time when the woman felt urge to push whereas the active pushing appeared to start later, which may have obscured an effect of the length of active pushing in our study.

We found an incidence of second-degree tears of $40.6 \%$, which is similar to the findings of Samuelsson et al. [1] but considerably lower than the incidence of $78.3 \%$ reported in the control group of an interventional study by Edqvist et al. [3]. Since the latter study was also conducted in a Swedish context and published as recently as 2017, explanations other than a true difference in the incidence due to diverging obstetric practice must be sought. Rather, diverging definitions of seconddegree tears could explain the difference. Our study and Samuelsson et al. [1] used the RCOG definitions of perineal tears [26], whereas Edqvist et al. classified vaginal tears with a depth $>0.5 \mathrm{~cm}$ as second-degree tears [3]. Unexpectedly, we found positions with reduced sacrum flexibility to be protective of seconddegree perineal tear. This contradicts the finding of Edqvist et al. [3], whose intervention including flexible sacrum positions significantly reduced seconddegree perineal tears. However, the evidence supporting any birth position to be superior to another in preventing perineal tears is limited [28, 29].

The incidence of OASI of $7.4 \%$ in the present study is among the highest reported to our knowledge. The majority of previous studies have reported a lower

Table 6 Unadjusted and adjusted odds ratios for the risk of second-degree perineal tear and obstetric anal sphincter injury by delivery mode and fetal weight

\begin{tabular}{|c|c|c|c|c|c|c|}
\hline \multirow[t]{2}{*}{$n=443$} & \multicolumn{3}{|c|}{ Second-degree perineal tear $(n=182)$} & \multicolumn{3}{|c|}{ Obstetric anal sphincter injury $(n=31)$} \\
\hline & $\begin{array}{l}\text { Incidence } \\
\text { (n) }\end{array}$ & $\begin{array}{l}\text { OR } \\
(95 \% \mathrm{Cl})\end{array}$ & $\begin{array}{l}\text { aOR } \\
(95 \% \mathrm{Cl})\end{array}$ & $\begin{array}{l}\text { Incidence } \\
\text { (n) }\end{array}$ & $\begin{array}{l}\text { OR } \\
(95 \% \mathrm{Cl})\end{array}$ & $\begin{array}{l}\text { aOR } \\
(95 \% \mathrm{Cl})\end{array}$ \\
\hline $\begin{array}{l}\text { Spontaneous delivery and fetal weight }<4000 \mathrm{~g}(n= \\
335)\end{array}$ & 126 & Reference & Reference & 14 & Reference & Reference \\
\hline $\begin{array}{l}\text { Spontaneous delivery and fetal weight } \geq 4000 \mathrm{~g} \text { ( } n= \\
\text { 49) }\end{array}$ & 24 & $\begin{array}{l}2.32(1.19 \\
4.54)^{*}\end{array}$ & $2.22(1.1,4.51)^{*}$ & 9 & $7.83(2.94,20.9)$ & $7.7(2.71,21.8)^{*}$ \\
\hline Vacuum extraction and fetal weight $<4000 \mathrm{~g}(n=45)$ & 23 & $\begin{array}{l}2.22(1.13 \\
4.37)^{*}\end{array}$ & $\begin{array}{l}2.41(1.16 \\
5.02)^{*}\end{array}$ & 6 & $\begin{array}{l}5.22(1.77 \\
15.4)^{*}\end{array}$ & $\begin{array}{l}5.52(1.62 \\
18.8)^{*}\end{array}$ \\
\hline Vacuum extraction and fetal weight $\geq 4000 \mathrm{~g}(n=17)$ & 9 & $\begin{array}{l}4.64(1.23 \\
17.5)^{*}\end{array}$ & $4.8(1.20,19.3)^{*}$ & 2 & $\begin{array}{l}9.29(1.43 \\
60.2)^{*}\end{array}$ & $\begin{array}{l}12.7(1.65 \\
97.7)^{*}\end{array}$ \\
\hline
\end{tabular}

Unadjusted and adjusted odds ratios for the risk of second-degree perineal tear and obstetric anal sphincter injury by delivery mode (spontaneous or vacuum extraction) and fetal weight $(<4000 \mathrm{~g}$ or $\geq 4000 \mathrm{~g})$. *Significant at level $p<0.05$. aOR adjusted odds ratio, $\mathrm{Cl}$ confidence interval, OR odds ratio 
incidence of OASI in primiparous women, ranging 5.1$6.7 \%[1,2,4]$, although one study found a higher incidence of $8.3 \%$ [5]. Obstetric management may partly explain our high incidence, such as the comparably frequent use of instrumental delivery of $18.2 \%$ in our study. The accuracy of incidence data must also be addressed when comparing studies. A validity study reported that one of four hospital discharges associated with OASI were undercoded [30], thus questioning the results of retrospective studies based on discharge codes. Finally, the incidence of OASI in epidemiologic studies, including ours, almost exclusively relies on clinical diagnosis of OASI. Clinical diagnosis of OASI is known to be difficult, generally underestimating the incidence compared to endoanal sonography [31].

The use of episiotomy poses a challenge when studying second-degree perineal tears since episiotomy technically is a second-degree tear, however iatrogenic. A woman having an episiotomy must be considered to have a second-degree perineal tear at a minimum since an episiotomy appears to be associated with at least the same risk of complications and chronic ailments as a spontaneous second-degree tear [14]. However, including women having an episiotomy when studying incidence and risk factors of second-degree perineal tears exaggerate the incidence of the latter and confound the analysis of risk factors. Consequently we excluded the women with episiotomy when calculating incidence and analyzing risk factor of perineal tears. Although the exclusion may be seen to reduce the generalizability of our results, the analysis including the women with episiotomy showed similar results to our main analysis.

Obstetric risk factors for perineal tears are often interrelated, as is the case for the two largest risk factors identified in this study: birth weight $>4000 \mathrm{~g}$ and vacuum extraction. This was the rationale for the stratification of subgroups according to these risk factors (Table 6). The odds of OASI in the subgroup with the two major risk factors combined was markedly high; more than tenfold higher than the reference category, even though there was no evidence of positive effect modification and confidence intervals were wide.

High vaginal tear was fairly common in our study, affecting $14.0 \%$ of women. Our review of the literature found only two studies specifically reporting the incidence of vaginal tears, ranging $7.8-35.1 \%$, irrespective of parity [32, 33]. However, none of the studies reported the extension of vaginal tears, albeit one of the studies used a detailed protocol including information about the extension of vaginal tears [33]. We found no study exploring the risk factors of vaginal tears.

Vaginal sidewall tears might be an independent risk factor for levator ani avulsion [10], and hence could be a marker for increased future risk of pelvic floor dysfunction. Interestingly enough, we found that heredity of pelvic floor dysfunction and/or connective tissue deficiency was a risk factor for high vaginal tear. One might speculate that a genetic connective tissue deficiency resulting in an increased risk of levator ani avulsion is the link, which explains the finding above. Vacuum extraction has earlier been associated with increased risk of levator ani avulsion [34]. This possibly supports the present finding of vacuum extraction being a risk factor of high vaginal tear, given the association between vaginal sidewall tears and levator ani avulsion decribed above. The associations found between high vaginal tear and induction of labor and oxytocin augmentation respectively, we consider should be interpreted with caution.

Strengths of this study is the prospective data collection and the assessment of a wide range of risk factors. In the present study we used a validated protocol for documentation of perineal tears, which we have previously shown to deliver more comprehensive information about perineal tears than the most common obstetric record system in Sweden [25].

Although we examined a range of variables, there a several potential risk factors and protective factors not being considered in the present study. For example, we could not evaluate the application of warm compresses to the perineum during delivery or the use of antenatal perineal massage as protective factors, because these variables were not included in the study protocol or in any template of the obstetric record system.

The sample size of this prospective study (489 and 426 women included in the regression models of perineal tears and vaginal tears respectively) is smaller than in most retrospective studies in the field, which constitutes a limitation of the study. The limited sample size confers a risk of type II errors, and may partly explain why some previously described risk factors did not show the association. Our study was exploratory, and the associations suggested in our study may therefore be important to be examined with a study with greater sample size and higher previsions in data.

Data collected in a context of daily clinical practice may have led to imprecise recording of some variables. As discussed elsewhere, the definition of active second stage of labor varied, and the eye-assessment of high vaginal rupture cannot be claimed to be exact. Such misclassification of variables might have resulted in spurious significant associations or in underestimation of associations to a degree. On the other hand, the results from a study performed in a clinical context may be transferable to everyday practice to a higher extent, than the results from a controlled clinical trial.

\section{Conclusions}

The present study corroborates previous findings of vacuum extraction and fetal weight exceeding $4000 \mathrm{~g}$ as risk 
factors of OASI. We found that vacuum extraction is a risk factor for second-degree tear, and vacuum extraction, fetal head circumference exceeding $35 \mathrm{~cm}$ and heredity of pelvic floor dysfunction and/or connective tissue deficiency were associated with increased risk of high vaginal tears. These findings have not been documented previously. Sociodemographic factors did not appear to affect the risk for neither tear. Important findings were the high incidences of second-degree perineal tear and high vaginal tear, which have not been sufficiently examined before. Our results should be confirmed by additional studies.

\section{Supplementary Information}

The online version contains supplementary material available at https://doi. org/10.1186/s12884-020-03447-0.

Additional file 1.

Additional file 2

\section{Abbreviations}

OASI: Obstetric anal sphincter injury; POPRACT: Pelvic Floor In Pregnancy and Childbirth study

\section{Acknowledgements}

We wish to thank research coordinators Anette Trygg and Carina Henriksson who coordinated the data collection, and all the midwives and physicians involved in the inclusion of study participants and data collection.

\section{Authors' contributions}

MHJ: Project development, data collection, data analysis, manuscript writing. KF: Project development, data analysis, manuscript editing. AH: Data analysis, manuscript editing. GT: Data analysis, manuscript editing. HD: Data collection, data analysis, manuscript editing. KN: Project development, data analysis, manuscript editing. All authors have read and approved the manuscript.

\section{Funding}

This study was funded by ALF funding Region Örebro County (Grant Nos. OLL-839631 and OLL-930507), Region Örebro County Research Committee (Grant Nos. OLL-779831), Swedish Society of Medicine (Grant No. SLS250351) and Örebro University Hospital Research Foundation (Grant No. OLL410421). These funding bodies had no had no role in the design of the study and collection, analysis, and interpretation of data and in writing the manuscript. Open Access funding provided by Örebro University.

\section{Availability of data and materials}

The datasets used and analyzed during the current study are available from the corresponding author on reasonable request.

\section{Ethics approval and consent to participate}

Ethical approval was given by the Regional Ethical Review Board in Stockholm (registration number 2014/124-32). All participants gave written informed consent at inclusion into the study at maternity health care in early pregnancy.

\section{Consent for publication}

Not applicable.

\section{Competing interests}

The authors declare that they have no competing interests.

\section{Author details}

'Department of Obstetrics and Gynecology, Örebro University Hospital, Örebro, Sweden. ${ }^{2}$ School of Medical Sciences, Faculty of Health and
Medicine, Örebro University, SE-701 82 Örebro, Sweden. ${ }^{3}$ Unit of Obstetrics and Gynecology, CLINTEC, Karolinska University Hospital at Huddinge, Karolinska Institutet, Stockholm, Sweden. ${ }^{4}$ Department of Surgery, Örebro University Hospital, Örebro, Sweden.

Received: 30 April 2020 Accepted: 20 November 2020

Published online: 02 December 2020

\section{References}

1. Samuelsson E, Ladfors L, Lindblom BG, Hagberg H. A prospective observational study on tears during vaginal delivery: occurrences and risk factors. Acta Obstet Gynecol Scand. 2002;81(1):44-9.

2. Smith LA, Price N, Simonite V, Burns EE. Incidence of and risk factors for perineal trauma: a prospective observational study. BMC Pregnancy Childbirth. 2013;13:59.

3. Edqvist M, Hildingsson I, Mollberg M, Lundgren I, Lindgren H. Midwives' Management during the second stage of labor in relation to second-degree tears-an experimental study. Birth. 2017:44(1):86-94.

4. Jango H, Langhoff-Roos J, Rosthoj S, Sakse A. Modifiable risk factors of obstetric anal sphincter injury in primiparous women: a population-based cohort study. Am J Obstet Gynecol. 2014;210(1):59.e51-6.

5. Ramm O, Woo VG, Hung Y-Y, Chen H-C, Ritterman Weintraub ML. Risk factors for the development of obstetric anal sphincter injuries in modern obstetric practice. Obstet Gynecol Annu. 2018:131(2):290-6.

6. Statistics on Pregnancies. Deliveries and newborn infants 2016. Stockholm: The National Board of Health and Welfare; 2018.

7. Evers EC, Blomquist JL, McDermott KC, Handa VL. Obstetrical anal sphincter laceration and anal incontinence 5-10 years after childbirth. Am J Obstet Gynecol. 2012;207(5):425.e421-426.

8. Radestad I, Olsson A, Nissen E, Rubertsson C. Tears in the vagina, perineum, sphincter ani, and rectum and first sexual intercourse after childbirth: a nationwide follow-up. Birth. 2008;35(2):98-106.

9. Tegerstedt G, Miedel A, Maehle-Schmidt M, Nyren O, Hammarstrom M. Obstetric risk factors for symptomatic prolapse: a population-based approach. Am J Obstet Gynecol. 2006;194(1):75-81.

10. Shek KL, Green K, Hall J, Guzman-Rojas R, Dietz HP. Perineal and vaginal tears are clinical markers for occult levator ani trauma: a retrospective observational study. Ultrasound Obstet Gynecol. 2016;47(2):224-7.

11. Aasheim V, ABV N, Reinar LM, Lukasse M. Perineal techniques during the second stage of labour for reducing perineal trauma. Cochrane Database Systematic Rev. 2017:6:Cd006672.

12. de Leeuw JW, de Wit C, Kuijken JP, Bruinse HW. Mediolateral episiotomy reduces the risk for anal sphincter injury during operative vaginal delivery. BJOG. 2008;115(1):104-8.

13. Revicky V, Nirmal D, Mukhopadhyay S, Morris EP, Nieto JJ. Could a mediolateral episiotomy prevent obstetric anal sphincter injury? Eur J Obstet Gynecol Reprod Biol. 2010;150(2):142-6.

14. Jiang H, Qian X, Carroli G, Garner P. Selective versus routine use of episiotomy for vaginal birth. Cochrane Database Systematic Rev. 2017;2: cd000081.

15. Poulsen MO, Madsen ML, Skriver-Moller AC, Overgaard C. Does the Finnish intervention prevent obstetric anal sphincter injuries? A systematic review of the literature. BMJ Open. 2015;5(9):e008346

16. Elvander C, Ahlberg M, Thies-Lagergren L, Cnattingius S, Stephansson O. Birth position and obstetric anal sphincter injury: a population-based study of 113000 spontaneous births. BMC Pregnancy Childbirth. 2015;15:252.

17. Samuelsson E, Ladfors L, Wennerholm UB, Gåreberg B, Nyberg K, Hagberg H. Anal sphincter tears: prospective study of obstetric risk factors. 2000; 107(7):926-31

18. Zetterstrom J, Lopez A, Anzen B, Norman M, Holmstrom B, Mellgren A. Anal sphincter tears at vaginal delivery: risk factors and clinical outcome of primary repair. Obstet Gynecol. 1999;94(1):21-8.

19. Donnelly V, Fynes M, Campbell D, Johnson H, O'Connell PR, O'Herlihy C. Obstetric events leading to anal sphincter damage. Obstet Gynecol. 1998; 92(6):955-61.

20. Andrews V, Sultan AH, Thakar R, Jones PW. Risk factors for obstetric ana sphincter injury: a prospective study. Birth. 2006:33(2):117-22.

21. Tegerstedt G, Miedel A, Maehle-Schmidt M, Nyren O, Hammarstrom M. A short-form questionnaire identified genital organ prolapse. J Clin Epidemiol. 2005;58(1):41-6. 
22. Luthander C, Emilsson T, Ljunggren G, Hammarstrom M. A questionnaire on pelvic floor dysfunction postpartum. Int Urogynecol J. 2011;22(1):105-13.

23. Franzen K, Johansson JE, Karlsson J, Nilsson K. Validation of the Swedish version of the incontinence impact questionnaire and the urogenital distress inventory. Acta Obstet Gynecol Scand. 2013;92(5):555-61.

24. Teleman P, Stenzelius K, lorizzo L, Jakobsson U. Validation of the Swedish short forms of the pelvic floor impact questionnaire (PFIQ-7), pelvic floor distress inventory (PFDI-20) and pelvic organ prolapse/urinary incontinence sexual questionnaire (PISQ-12). Acta Obstet Gynecol Scand. 2011;90(5):4837.

25. Jansson MH, Nilsson K, Franzen K. Development and validation of a protocol for documentation of obstetric perineal lacerations. Int Urogynecol J. 2019;30(12):2069-76.

26. The management of third- and fourth-degree perineal tears. Green-Top Guideline No. 29. London: Royal College of Obstetricians and Gynaecologists; 2015.

27. World Health O. ICD-10 : international statistical classification of diseases and related health problems / World Health Organization. Geneva: World Health Organization; 2004

28. Gupta JK, Sood A, Hofmeyr GJ, Vogel JP. Position in the second stage of labour for women without epidural anaesthesia. Cochrane Database Systematic Rev. 2017;5:Cd002006.

29. Walker KF, Kibuka M, Thornton JG, Jones NW. Maternal position in the second stage of labour for women with epidural anaesthesia. Cochrane Database Systematic Rev. 2018;11:Cd008070.

30. Brubaker L, Bradley CS, Handa VL, Richter HE, Visco A, Brown MB, Weber AM. Anal sphincter laceration at vaginal delivery: is this event coded accurately? Obstet Gynecol. 2007;109(5):1141-5.

31. Corton MM, McIntire DD, Twickler DM, Atnip S, Schaffer Jl, Leveno KJ. Endoanal ultrasound for detection of sphincter defects following childbirth. Int Urogynecol J. 2013;24(4):627-35.

32. Kimmich N, Grauwiler V, Richter A, Zimmermann R, Kreft M. Birth lacerations in different genital compartments and their effect on maternal subjective outcome: a prospective observational study. Z Geburtshilfe Neonatol. 2019; 223(6):359-68.

33. Birri J, Kreft M, Zimmermann R, Kimmich N. Association of Birth Trauma with the implementation of obstetrical monitoring tools: a retrospective cohort study. Z Geburtshilfe Neonatol. 2019;223(3):157-68.

34. Caudwell-Hall J, Kamisan Atan I, Martin A, Guzman Rojas R, Langer S, Shek K, Dietz HP. Intrapartum predictors of maternal levator ani injury. Acta Obstet Gynecol Scand. 2017;96(4):426-31.

\section{Publisher's Note}

Springer Nature remains neutral with regard to jurisdictional claims in published maps and institutional affiliations.

Ready to submit your research? Choose BMC and benefit from:

- fast, convenient online submission

- thorough peer review by experienced researchers in your field

- rapid publication on acceptance

- support for research data, including large and complex data types

- gold Open Access which fosters wider collaboration and increased citations

- maximum visibility for your research: over $100 \mathrm{M}$ website views per year

At $\mathrm{BMC}$, research is always in progress.

Learn more biomedcentral.com/submissions 